\title{
PARQUES URBANOS DE PORTO ALEGRE: ESTRUTURA ORGANIZACIONAL E GESTÃO
}

\author{
SOUZA, Alex Pereira de \\ UFRGS, e-mail: arquitetoalexsouza@gmail.com \\ MIRON, Luciana Inês Gomes \\ UFRGS, e-mail: Iumiron@gmail.com
}

\begin{abstract}
RESUMO
Este trabalho, tem por objetivo analisar a gestão dos parques urbanos de Porto Alegre, através da evolução da estrutura organizacional da Secretaria gestora, a Secretaria do Meio Ambiente e da Sustentabilidade (SMAMS). A coleta de dados foi realizada através de: revisão de literatura sobre gestão e planejamento de parques urbanos; análise de documentos; análise de legislações e de entrevistas informais com técnicos da SMAMS sobre a atual forma de gestão dos parques da cidade. A partir dos resultados, o estudo busca oportunizar uma reflexão sobre as práticas atuais de gerenciamento de parques, suscitando a necessidade de rever os métodos aplicados afim de garantir parques urbanos de melhor qualidade.
\end{abstract}

Palavras-chave: parques urbanos, estrutura organizacional, gestão de parques.

\begin{abstract}
The objective of this work is to analyze the management of urban parks in Porto Alegre, through the evolution of the organizational structure of the Management Secretariat, the Secretariat for the Environment and Sustainability (SMAMS). Data collection was performed through: literature review on urban park management and planning; document Analysis; analysis of legislations and informal interviews with SMAMS technicians on the current management of the city's parks. From the results, the study seeks to provide a reflection on the current practices of park management, provoking the need to review the applied methods in order to guarantee urban parks of better quality.
\end{abstract}

Keywords: Urban parks, organizational structure, park management.

\section{INTRODUÇÃO}

Os parques urbanos surgiram no final do século XVIII e foram projetados para melhorar a qualidade de vida e lazer dos habitantes da era industrial, segundo Macedo (2002). No Brasil, o primeiro espaço público ocorreu pela construção do Passeio Público no Rio de Janeiro no ano de 1783. As definições para parques urbanos são diversas, na opinião de Macedo (2003), o parque é um espaço livre e público, destinado ao lazer de massa urbana e estruturado por vegetação. Outra definição encontrada em Macedo (1999), sinaliza que os parques são espaços públicos voltados ao lazer, esporte, contemplação e interação social. Representam elementos estruturadores do tecido urbano, com áreas predominantemente não edificadas, que contribuem para 0 equilíbrio ambiental da Cidade. Conforme informado pela Secretaria do Meio Ambiente e da Sustentabilidade (SMAMS), em Porto Alegre, os parques urbanos são caracterizados por possuir área com mais de $10.000 \mathrm{~m}^{2}$, presença de sede administrativa e banheiros públicos. Além disso, possuem por

SOUZA, A.; MIRON, L. Parques urbanos de Porto Alegre: Estrutura organizacional e Gestão. In: SIMPÓSIO BRASILEIRO DE QUALIDADE DO PROJETO NO AMBIENTE CONSTRUÍDO, 6., 2019, Uberlândia. Anais... Uberlândia: PPGAU/FAUeD/UFU, 2019. p. 192-197. DOI https://doi.org/10.14393/sbqp19019. 
característica a abrangência regional e não apenas local, como se caracteriza a maioria das praças.

Segundo (FEIX, 2003), ainda em 1924 os espaços abertos de Porto Alegre se incorporaram a vida da cidade de uma das capitais brasileiras com maior quantidade de praças, parques, campos de várzeas somando uma grande área verde no espaço urbano qualificando a vida dos cidadãos. "A comunidade os utiliza no seu dia a dia das mais variadas formas como possibilidade de melhorar a saúde, oportunizar as relações com os outros e valorizar sua própria existência", conforme relato da época. O costume da comunidade frequentar parques e praças é uma tradição antiga de Porto Alegre, onde os locais foram especialmente planejados e equipados para as práticas esportivas de ginastica e de recreação. Com o movimento mundial da educação física no início do século XX, a partir de 1926 a capital gaúcha começava a empenhar-se na institucionalização da recreação pública, criando serviços e profissionais técnicos à disposição da população nos parques, praças e balneários afim de propiciar aos usuários a sociabilidade, o entretenimento, a saúde, o esporte, a recreação, a cultura e o congraçamento da comunidade abrangendo diversas faixas etárias. (FEIX, 2003).

Dados do IBGE (2010) apontam que porto alegre possui uma população de 1.209.351 habitantes e uma densidade de $2.857 .53 \mathrm{hab} / \mathrm{km}^{2}$. A cidade possui 09 parques urbanos, a saber: Moinhos de Vento (Parcão), Gabriel Knijinik, Marechal Mascarenhas de Moraes, Farroupilha (Redenção), Marinha do Brasil, Maurício Sirotksky Sobrinho (Harmonia), Chico Mendes, Alemanha (Germânia) e recentemente o Parque da Orla Moacyr Scliar. A gestão dessas áreas envolve diferentes setores e secretarias da Prefeitura Municipal, sendo a Secretaria responsável pela gestão, a SMAMS - Secretaria do Meio Ambiente e da Sustentabilidade.

Cabe destacar os conceitos de Planejamento e Gestão: Segundo SOUZA (2010), o Planejamento está ligado a ideia de futuro, visa tentar simular os desdobramentos de um processo, com o objetivo de melhor precaver-se contra prováveis problemas ou, inversamente, com fito de tirar melhor partido de prováveis benefícios. Já a Gestão está ligado a ideia de presente, significa administrar uma situação dentro dos marcos dos recursos previamente disponíveis e tendo em vista as necessidades imediatas. Longe de serem termos concorrentes ou intercambiáveis, são distintos e complementares. "A Gestão é a efetivação das condições que o planejamento ajudou a construir". (SOUZA,2010). O autor ainda discorre que "para sistematizar, podese assumir que o desenvolvimento urbano, o qual é o objetivo fundamental do planejamento e gestão urbanos, deixa-se definir com a ajuda de dois objetivos derivados: a melhoria da qualidade de vida e o aumento da justiça social". Os desafios para uma perspectiva socialmente crítica do planejamento e da gestão urbanos perpassam por vários aspectos, dentre os quais, a análise crítica da estrutura e modelo de gestão, afim de qualificar procedimentos e implementar um planejamento para as áreas verdes públicas de lazer. (Souza, 2008).

Para CARMONA (2010), A gestão do espaço público é tomada como uma esfera de governança urbana na qual as demandas sociais e as aspirações do espaço público conflituosas são interpretadas por meio de um conjunto de processos e práticas. Quatro dimensões interligadas para a gestão do espaço público são propostas: a coordenação de intervenções; a regulação de usos 
e conflitos entre usos; a definição e implantação de rotinas de manutenção; e investimento em espaços públicos e seus serviços. A Gestão de espaço público, representa o conjunto de processos e práticas que tentam garantir que o espaço público possa cumprir todos os seus papéis legítimos, gerenciando ao mesmo tempo as interações e os impactos dessas múltiplas funções de maneira aceitável para seus usuários. (CARMONA, 2010).

É importante destacar a evolução histórica das áreas verdes de Porto Alegre. Segundo dados obtidos pela Secretaria Gestora - SMAMS, no ano de 1976 existiam 147 praças urbanizadas e 03 parques urbanos. Atualmente em 2018 são 09 parques urbanos, 637 praças urbanizadas e 234 praças não urbanizadas. Observa-se que ocorreu um crescente número de áreas verdes e pressupõem-se que a estrutura de gestão não acompanhou o mesmo crescimento. O reflexo é percebido através das dificuldades enfrentadas pela gestão pública em gerenciar suas áreas verdes públicas de lazer. Este trabalho, tem por objetivo analisar a gestão dos parques urbanos de Porto Alegre, através da evolução da estrutura organizacional da SMAMS.

\section{METODOLOGIA}

Essa pesquisa foi iniciada por uma revisão de literatura. Em sequência, a fase exploratória de coleta e análise de dados foi realizada através de: análise de documentos; análise de legislações e entrevistas informais com técnicos da SMAMS.

\section{RESULTADOS E DISCUSSÃO}

\subsection{Evolução estrutura organizacional SMAMS}

A Secretaria do Meio Ambiente (SMAM), criada em 1976, foi a primeira Secretaria voltada aos cuidados com o meio ambiente no Brasil, precursora para os demais órgãos ambientais que foram criados a nível estadual e federal. No organograma original, a SUPPJ (1976) - Supervisão de Parques, Praças e Jardins, ficou com a responsabilidade pela gestão das áreas verdes públicas de lazer, englobando a Divisão de Projetos e Construção (DPC), responsável por aprovar e desenvolver projetos para as áreas verdes públicas de lazer, além de possuir o cadastro dessas áreas e ser responsável pela execução e fiscalização de obras. Também a Divisão de Conservação e Manutenção (DCM), responsável por manter e conservar os equipamentos existentes em parques e praças. A Divisão de Administração de Parques Praças e Jardins (DAPPJ), foi criada para gerenciar e planejar parques e praças, entretanto no decorrer do tempo, com as necessidades de administrar a arborização urbana, acabou deixando renegado seu papel de administrar os parques, incorporando em sua rotina as necessidades de manejo da arborização urbana. Houve a tentativa de implementar a Divisão de Administração de Parques (DAP), congregando todos os gerentes de parques e servidores operacionais, no entanto, acabou extinta no início dos anos 2000 , ocasionando uma gestão sem diretrizes gerais e descentralizada dos parques urbanos. Através da Lei Complementar 817/2017, a Administração Pública Municipal, criou e extinguiu secretarias municipais, estabeleceu suas finalidades e competências e revogou legislações sobre o tema. A antiga SUPPJ (Supervisão de Parques, Praças e Jardins), deu origem a CAV (Coordenação de Áreas Verdes). 


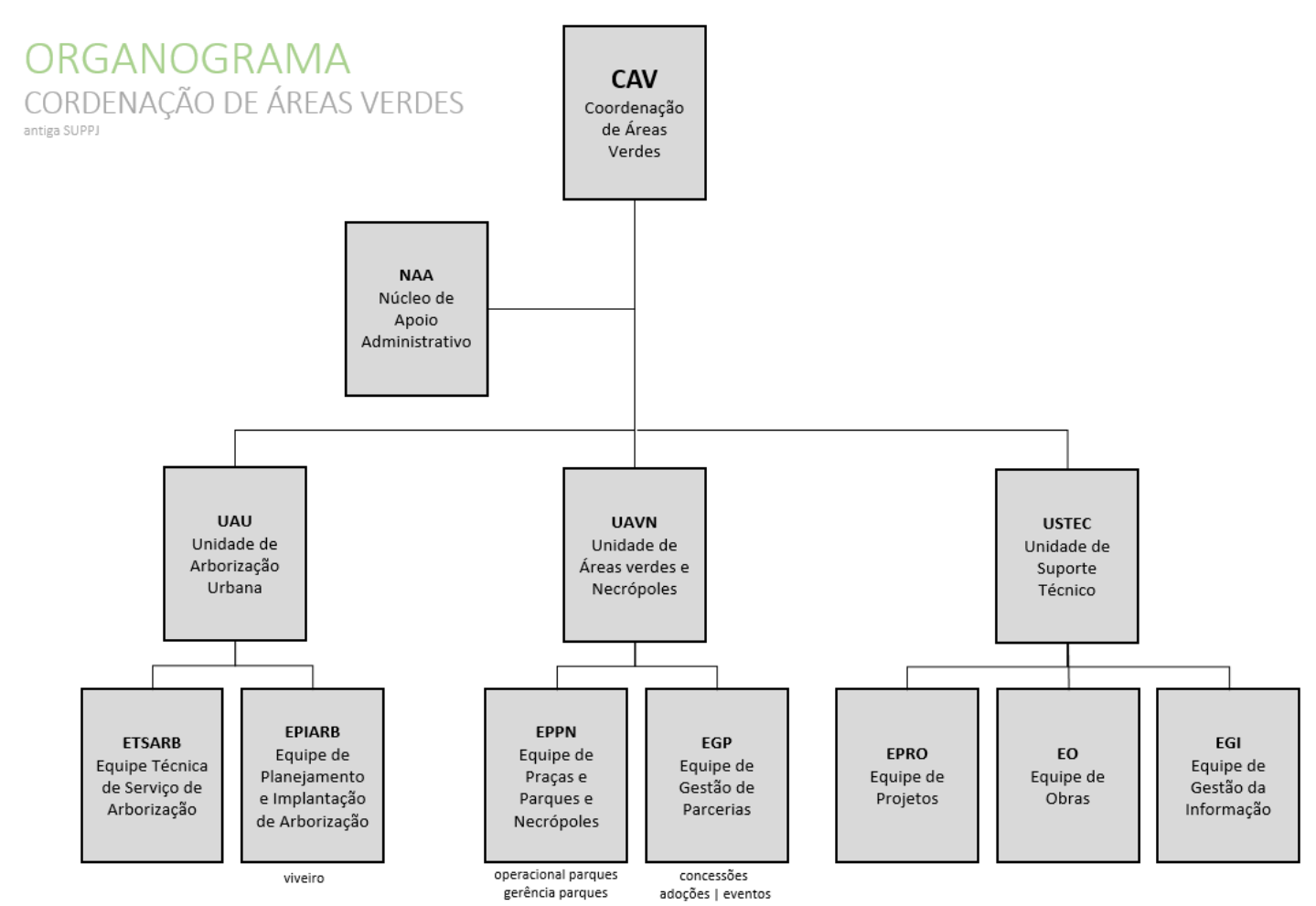

Figura 1 - Organograma da Coordenação de Áreas Verde Fonte: SMAMS (2018)

\subsection{Administração parques urbanos em Porto Alegre}

A gestão das áreas verdes municipais envolve diferentes setores e secretarias da Prefeitura Municipal de Porto Alegre - PMPA. Atualmente cada departamento faz isoladamente suas intervenções, gerando grande retrabalho em virtude da falta de comunicação entre os setores intervenientes. Recentemente foi criada a Unidade de Áreas Verdes e Necrópoles (UAVN), afim de organizar os fluxos e procedimentos necessários para atender as demandas de gestão e planejamento das Praças e Parques. Os técnicos da SMAMS informaram que atualmente está ocorrendo um período de transição na prestação de serviços nos parques urbanos. A maioria dos serviços conta com equipe própria da SMAMS, tais como: poda, roçada, capina, limpeza e recolhimento de lixo. A estimativa é que $80 \%$ dos servidores lotados nos parques se aposentem até 2020. Logo estão sendo desenvolvidos projetos que visam a contratação de empresas terceirizadas para os parques, como já ocorre com a Gestão das Praças, que tem sua manutenção executada/fiscalizada pela Secretaria Municipal de Serviços Urbanos SMSURB. Além disso, a adoção dos espaços públicos, programa implementado desde 1986, desonera o Município da manutenção dessas áreas e está em discussão na câmara de vereadores um projeto de lei que visa conceder parques e praças.

\subsection{Gestão de Parques Urbanos}

A gestão do espaço público é, de qualquer maneira, a esfera de governança em que as partes interessadas demandam e as aspirações para o espaço público são articuladas em conjuntos de processos e práticas. Dada a multifuncionalidade do espaço público, a variedade de partes interessadas 
cujas ações contribuem para moldar sua qualidade geral e a pluralidade de elementos que a constituem. "É claro que a gestão do espaço público é um conjunto complexo de atividades, que muitas vezes vai muito além do alcance dessas organizações, públicas ou privadas, formalmente encarregadas de entregá-las". (CARMONA 2010). Observa-se também a necessidade de modernizar processos administrativos para atender novas demandas. VAZ (2002), indica que a transformação das práticas de trabalho requer um conjunto de ações articuladas que vão além do redesenho de processos de trabalho e da reorganização da estrutura administrativa. "É preciso dar conta de promover mudanças significativas na cultura organizacional, através de ações de qualificação dos servidores públicos complementadas por iniciativas de motivação, envolvimento e resgate da sua dignidade".

Segundo CARMONA (2010), no Reino Unido existe a tendência de se aplicar três modelos emergentes de gestão do espaço público (três formas diferentes de abordar as questões de coordenação, regulação, manutenção e investimento). O primeiro modelo está centrado nos órgãos públicos desempenhando as funções de coordenadores, reguladores, mantenedores e financiadores. O segundo modelo estabelece a delegação parcial ou completa desses papéis a organizações do setor privado por meio de acordos contratuais e acordos recíprocos. E o terceiro modelo, semelhante ao segundo, mas os papéis são transferidos para organizações voluntárias e do setor comunitário, como parte de um movimento para reduzir a distância entre o usuário e o provedor dos serviços. Ao observar uma publicação do início desse século, DIAS (2005) afirma que: "Embora nos países desenvolvidos estejam ocorrendo grandes reestruturações nos parques urbanos, tal transformação não tem se estendido nos países sul-americanos, em especial no Brasil". Observamos que atualmente a disponibilidade de receitas para investimentos em áreas Os recursos são direcionados a áreas prioritárias. Encontrar maneiras de qualificar os parques urbanos frente a indisponibilidade de recursos, exige o conhecimento de novas maneiras de fazer gestão e planejamento. Segundo (Souza, 2010): "Seja como for, em uma época em que a capacidade regulatória e de investimento do Estado se acha, muito particularmente aos Estados super endividados da periferia e semiperiferia capitalistas, bastante reduzida, adotar modelos menos centralizadores e rígidos de planejamento não é apenas uma opção ideológica: é uma necessidade econômica e política".

\section{CONSIDERAÇÕES FINAIS}

O presente estudo possibilitou a identificação das modificações que foram ocorrendo na gestão pública de Porto Alegre ao longo dos anos para desenvolver as áreas verdes públicas de lazer. Observa-se no presente, um esforço por parte da SMAMS, a fim de qualificar os parques urbanos, seja por modificações em seu organograma visando atenção maior com essas áreas, seja por estudos que estão sendo desenvolvidos pelos técnicos da Secretaria, ou ainda pelas parcerias desenvolvidas com a iniciativa privada. Além disso, a secretaria está desenvolvendo acordos de cooperação técnica visando a aplicação dos melhores procedimentos aplicáveis a gestão de parques na cidade. Os resultados identificam a necessidade de alterar ou implementar novos procedimentos, rotinas e a própria forma de fazer gestão. Para isso, 
dispor de instrumentos jurídicos e dispositivos de regulamentação e fiscalização para garantir parques urbanos de melhor qualidade.

\section{AGRADECIMENTOS}

Ao CNPq e à CAPES, pelo apoio recebido.

\section{REFERÊNCIAS}

CARMONA,M. MAGALHÃES, C.; HAMMOND, L. Public space : The management dimension. Routledge, 2008.

DIAS, Fabiano. O desafio do espaço público nas cidades do século XXI. Arquitextos, São Paulo, 06.601, Vitruvius, 2005.

FEIX, Eneida. Lazer e cidade na Porto Alegre no início do século XX: a institucionalização da recreação pública. Porto Alegre: Dissertação de mestrado em educação. UFRGS, 2003.

IBGE - Instituto Brasileiro De Geografia E Estatística, 2010.

MACEDO, S. S.; ROBBA, F. Parques Urbanos no Brasil. São Paulo: Edusp, 2002.

MACEDO, S. S. Quadro do Paisagismo no Brasil. São Paulo, 1999.

SOUZA, M. L. Mudar a cidade: uma introdução crítica ao planejamento e à gestão urbanos. $7^{a}$ ed. - Rio de Janeiro: Bertrand Brasil, 2010.

VAZ. J.C. Novos contornos da gestão local: conceito em construção. Texto: Desafios para incorporação da transparência em um modelo de gestão municipal. São Paulo. Pólis, 2002. 